\title{
REVIEW
}

\section{IIIIII Diabetes and Cardiovascular Care Among People with Severe Mental Illness: A Literature Review}

\author{
Christina Mangurian, MD, MAS ${ }^{1,2,3}$, John W. Newcomer, $M D^{4}$, Chelsea Modlin, $B A^{5}$, and \\ Dean Schillinger, $M D^{2,3,6}$
}

'Department of Psychiatry, University of California, San Francisco (UCSF), San Francisco, CA, USA; ${ }^{2}$ UCSF Center for Vulnerable Populations at ZSFG, San Francisco, CA, USA; ${ }^{3}$ Zuckerberg San Francisco General, San Francisco, CA, USA; ${ }^{4}$ Florida Atlantic University, Boca Raton, FL, USA; 5 Geisel School of Medicine, Dartmouth University, Hanover, NH, USA; ' UCSF Department of Medicine, San Francisco, CA, USA.

Close to 19 million US adults have severe mental illnesses (SMI), and they die, on average, 25 years earlier than the general population, most often from cardiovascular disease (CVD). Many of the antipsychotic medications used to treat SMI contribute to CVD risk by increasing risk for obesity, type 2 diabetes, dyslipidemia, and hypertension. Based on compelling evidence, the American Diabetes Association and the American Psychiatric Association developed guidelines for metabolic screening and monitoring during use of these medications.

In this manuscript, we have reviewed the evidence on diabetes and other CVD risk screening, prevalence, and management among populations with SMI. We also review differences in screening among subpopulations with SMI (e.g., racial/ethnic minorities, women, and children). We found that despite national guidelines for screening for diabetes and other cardiovascular risk factors, up to $70 \%$ of people taking antipsychotics remain unscreened and untreated. Based on estimates that $20 \%$ of the 19 million US adults with SMI have diabetes and $70 \%$ of them are not screened; it is likely that over 2 million Americans with SMI have unidentified diabetes. Given that undiagnosed diabetes costs over $\$ 4,000$ per person, this failure to identify diabetes among people with SMI represents a missed opportunity to prevent morbidity and translates to over $\$ 8$ billion in annual preventable costs to our healthcare system.

Given the high burden of disease and significant evidence of suboptimal medical care received by people with SMI, we propose several clinical and policy recommendations to improve diabetes and other CVD risk screening and care for this highly vulnerable population. These recommendations include reducing antipsychotic medication dose or switching antipsychotic medications, enhancing smoking cessation efforts, sharing electronic health records between physical and mental health care systems, and promoting integration of care.

KEY WORDS: mental illness; diabetes; integration of care.

J Gen Intern Med 31(9):1083-91

DOI: $10.1007 / \mathrm{s} 11606-016-3712-4$

(c) Society of General Internal Medicine 2016

Received November 13, 2015

Revised March 17, 2016

Accepted April 5, 2016

Published online May 5, 2016

\section{CASE}

Mr. Ortiz is a 46-year-old Latino man with schizophrenia with a history of multiple psychiatric hospitalizations and multiple suicide attempts in the setting of command auditory hallucinations. He sees a community mental health clinic psychiatrist (Dr. Barton) monthly, who manages his auditory hallucinations and paranoia with risperidone. Mr. Ortiz is overweight, smokes, and has hypertension. After a recent metabolic panel, Mr. Ortiz was found to have prediabetes. Dr. Barton and Mr. Ortiz discussed switching from risperidone to a medication with less metabolic risk, but because of prior medication failures and serious psychiatric decompensations, they decided to stay on the risperidone for now. Dr. Barton urges Mr. Ortiz to see his primary care provider at another clinic across town, but the patient has been reluctant despite several attempts by his case manager. Dr. Barton is considering starting metformin, but has never initiated this medication before and feels uncomfortable doing this without a primary care provider's guidance.

\section{INTRODUCTION}

The prevalence of severe mental illness (SMI; e.g., schizophrenia, bipolar disorder) has been estimated to be about $6 \%$ of the US population, or 19 million people nationwide. ${ }^{1,2}$ Although the majority of people with SMI are cared for in mental health care settings, primary care physicians - particularly those serving safety net populations - often see these patients as well. ${ }^{3,4}$ People with SMI die on average 25 years earlier than the general population, most often from premature cardiovascular disease (CVD). ${ }^{5-7}$ This mortality gap represents a formidable health care disparity, leading to calls by the Surgeon General and the Institute of Medicine for increased public health attention in this area. ${ }^{8,9}$ Secondgeneration antipsychotic medications (SGAs) contribute to this CVD risk ${ }^{10-12}$ and dominate the US antipsychotic medication market. $^{13,14}$

\section{SMI and Cardiovascular Disease}

People with SMI have higher rates of the metabolic syndrome and CVD compared to the general population (40\% vs. 
$30 \%)^{5,6,15-18}$ In the Clinical Antipsychotic Trials of Intervention Effectiveness (CATIE) schizophrenia trial, a large National Institutes of Mental Health-funded pragmatic clinical trial $(N=1460)$, the 10 -year coronary heart disease risk was significantly higher among people with schizophrenia than among a randomly selected, age-, gender-, and race/ ethnicity-matched National Health and Nutrition Examination Survey (NHANES) reference group (men $9.4 \%$ vs. $7.0 \%$; women $6.3 \%$ vs. $4.2 \%, p<0.001) .{ }^{17}$ In the fasting subset of the CATIE study population $(N=689)$, the prevalence of the metabolic syndrome was $36 \%$ among people with schizophrenia - significantly higher than the $20 \%$ prevalence observed in a randomly selected age-, gender-, and race/ethnicity-matched NHANES reference group. ${ }^{15,19}$

\section{SMI and Tobacco Use}

Smoking rates among the SMI population are remarkably high $(59 \%$ of people with schizophrenia smoking vs $18 \%$ in the general population). ${ }^{20-22}$ The CATIE trial found similarly high smoking rates among CATIE participants compared to matched NHANES controls (men $73 \%$ vs. $37 \%, p<0.0001$; women $56 \%$ vs. $28 \%, p<0.0001$ ). Unfortunately, internal tobacco industry documents highlight a targeted effort to increase smoking in this population through provision of cigarettes in psychiatric settings, blocking hospital smoking bans, and funding research claiming people with schizophrenia were less susceptible to the harms of tobacco and needed tobacco as self-medication. ${ }^{23}$ There is strong evidence that tobacco use is an important remediable factor that contributes to high risk for $\mathrm{CVD}^{24}$ In addition to smoking, other behavioral factors are prevalent among this population, including poor diet and lack of exercise. ${ }^{25}$

\section{SMI and Type 2 Diabetes}

People with SMI have much higher risk of developing diabetes. ${ }^{26}$ In a recent a meta-analysis, people with SMI had a pooled risk ratio for type 2 diabetes of 1.70 (1.21-2.37) (Fig. 1). ${ }^{26}$ When restricting analysis to people with schizophrenia, the risk of diabetes increases to 1.87 (1.68-2.09). In the Schizophrenia Patient outcomes Research Team (PORT) field study of people with schizophrenia from 1994 to 1996, the age-adjusted prevalence of self-reported diabetes was close to $15 \%$, almost twice as high as the U.S. population $(9.3 \%){ }^{27,28}$ Since that time, other reports suggest even higher rates, with the prevalence of diabetes in people with SMI typically being twofold to threefold higher than age-matched samples from the general population. ${ }^{10,29-35}$ We are aware of only two large studies examining pre-diabetes among people with schizophrenia. ${ }^{36,37}$ One study of older veterans with schizophrenia (mean age $59.6 \mathrm{yrs}$ ) screened for diabetes $(N=12,587,>95 \%$ men) found that $42 \%$ of these patients had pre-diabetes, which is comparable to $50 \%$ of U.S. elderly adults. ${ }^{28,36}$ In a European cohort of adult psychiatric inpatients
$(N=413), 37 \%$ had prediabetes, which is comparable to the general population. ${ }^{28,37}$

\section{Antipsychotic Medications and Cardiometabolic Risk}

Consistent evidence from a large number of studies using a variety of research methodologies indicates that many SGAs increase risk for obesity, dyslipidemia, type 2 diabetes and other metabolic abnormalities, with similar evidence for some first generation antipsychotics, although fewer studies have focused on these medications due to reduction in their use over the past two decades. ${ }^{15,16,38,39}$ Notably, different antipsychotics are associated with different levels of metabolic risk (Table 1)..$^{39,41,42}$ For example, risk for weight gain and obesity, a well-established risk factor for both diabetes and cardiovascular disease, is generally highest for clozapine, olanzapine and low potency phenothiazines, like the first-generation antipsychotic (FGA) chlorpromazine. ${ }^{39}$ There is substantially lower but still intermediate risk for weight gain and obesity with risperidone, quetiapine, asenapine, and iloperidone, as well as high potency FGAs like haloperidol and fluphenazine. ${ }^{39}$ There are lower levels of observed risk for weight gain and obesity for ziprasidone, aripiprazole and lurasidone. ${ }^{39}$ Risk for incident diabetes among large samples of SGA users is also highest for clozapine and olanzapine, but not insignificant for the other FGAs. ${ }^{41}$ The 10-year coronary heart disease risk differs significantly between antipsychotic agents, with olanzapine producing the greatest risk among medications studies in the CATIE trial. ${ }^{43}$

Proposed mechanisms for antipsychotic-induced weight gain and other metabolic effects include activity at the D2 receptor, antagonism (or inverse agonism) at 5HT2C, antagonism at 5HT2A serotonin receptors, antagonism at alpha (1A) adrenergic receptors and especially antagonism at histamine (H1) receptors. ${ }^{11,12,44-47}$ Weight gain has long been associated with centrally active drugs with high affinity for the H1 receptor, with $\mathrm{H} 1$ antagonism known to increase feeding and sedation. ${ }^{48,49}$ These combined mechanisms suggest that weight gain during antipsychotic treatment may be related to alterations in satiety signaling leading to increased energy intake, and increases in sedation leading to reduced energy expenditure.

\section{Screening for Type 2 Diabetes and other Cardiovascular Disease Risk Factors among People with SMI}

Because the evidence for medication-related risk for diabetes was so compelling, in 2004 the American Diabetes Association (ADA) the American Psychiatric Association (APA) recommended annual metabolic screening for anyone taking SGA medications, regardless of age or predisposing factors. ${ }^{50,51}$ Specifically, ADA/APA guidelines recommend quarterly weight and BMI measurements; annual monitoring of blood pressure, fasting glucose, and waist 
Diabetes

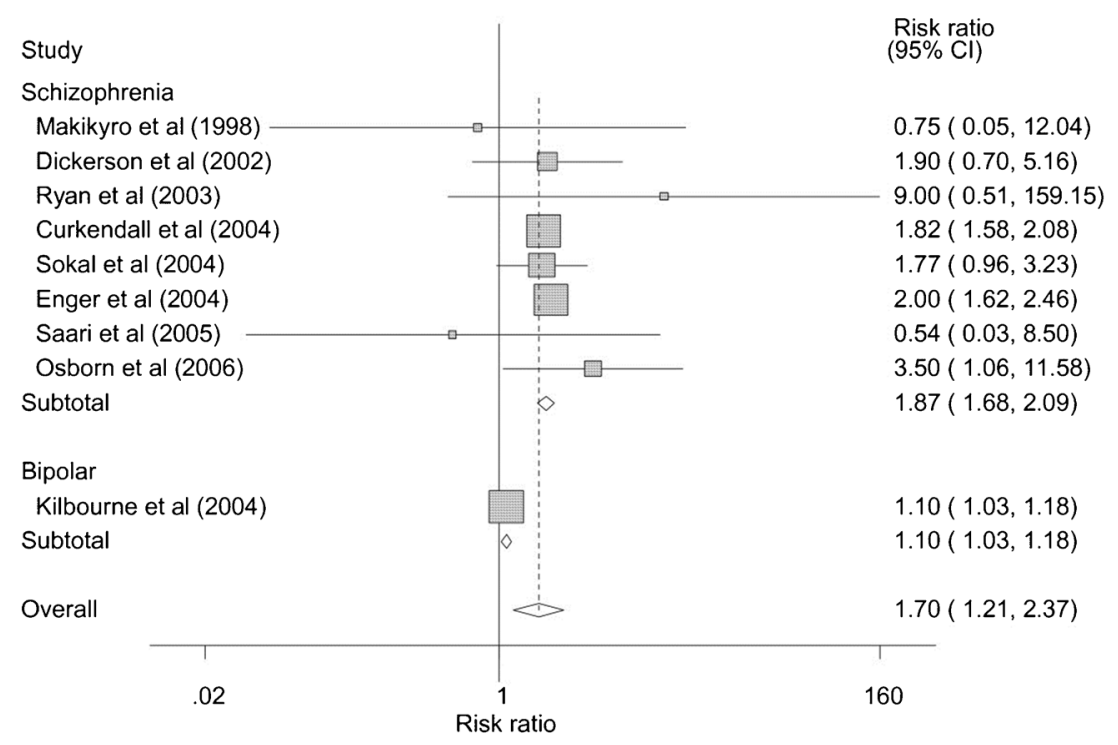

Figure 1. Risk of diabetes among people with SMI.* *Reprinted with permission from Osborn et al., BMC Psychiatry, 8:84, 2008. ${ }^{26}$

circumference; and fasting lipids every 5 years or "more frequently if clinically indicated." ${ }^{51}$ Unfortunately, over 10 years after publication of these diabetes screening guidelines, $70 \%$ of people taking SGAs remain unscreened for diabetes or dyslipidemia. ${ }^{52-56}$

Based on estimates that $20 \%$ of the 19 million US adults with SMI have diabetes ${ }^{26}$ and $70 \%$ of them are not screened for diabetes ${ }^{53,57}$; over 2 million Americans have unidentified diabetes. Given that undiagnosed diabetes costs over $\$ 4,000$ per person, ${ }^{58}$ this failure to identify diabetes among people with SMI represents a missed opportunity to prevent morbidity and translates into over $\$ 8$ billion in annual preventable costs to the healthcare system.
To our knowledge, there are no studies on preventing prediabetes progression to diabetes among people with SMI. Given evidence that treatment of pre-diabetes can prevent diabetes, ${ }^{59}$ lack of diabetes screening is a missed opportunity to prevent diabetes. ${ }^{60}$

\section{Management of Type 2 Diabetes and other Cardiovascular Disease Risk Factors among People with Comorbid SMI}

Even among populations with confirmed diabetes, people with SMI are less likely to receive recommended care or monitoring. ${ }^{61-64}$ In one VA study from $2001-2005$, only $11 \%$ of

Table 1. Antipsychotic Medication Side Effects*

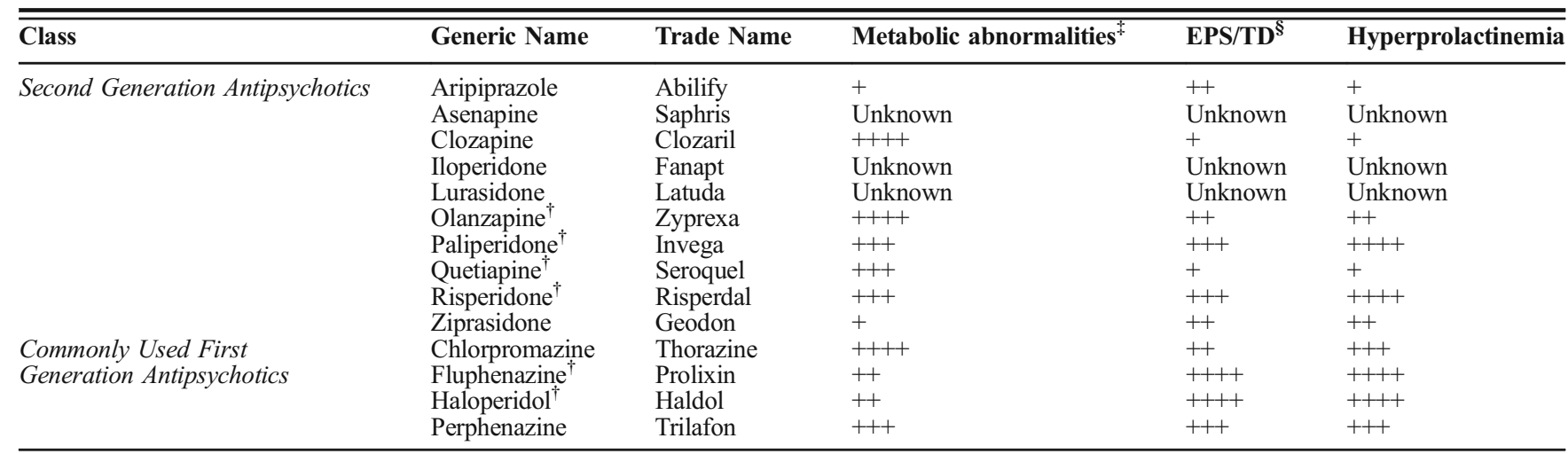

$+=$ minimal risk $++=$ low risk $+++=$ moderate risk $++++=$ high risk

+ Long-acting injectables are assumed to have the same side effect profile as the oral preparations. However, some advantages for long-acting preparations due to more uniform serum concentrations may be possible

$\neq$ Given the significant overlap in risk, weight gain, lipid abnormalities, and diabetes were combined into one category

$\S$ EPS $=$ Extrapyramidal symptoms: $T D=$ tardive dyskinesia

Sources: The primary source for all ratings is The 2009 Schizophrenia PORT Psychopharmacologic Treatment Recommendations and Summary Statements (Buchanan 2009). Since no single source covers all of the side effects for all drugs, additional sources for specific side effects include: Weight/metabolic (Newcomer 2005, Allison 1999, Nasrallah 2009), EPS/TD (Sadock 2007, Miyamoto 2008, Nasrallah 2009), and Hyperprolactinemia (Bushe 2008). Expert consultation was used when sources conflicted

* Adapted with permission from Dr. LloydSederer ${ }^{40}$ 
people with comorbid diabetes and SMI received medications to treat diabetes. ${ }^{36}$ In a community sample, among people with schizophrenia who reported they had diabetes, $41 \%$ reported not receiving antihyperglycemic treatment. ${ }^{65}$ In another study of diabetes patients, those with SMI were $29 \%$ less likely to be prescribed cholesterol-lowering statin medications, and $20 \%$ less likely to be prescribed angiotensin-converting enzyme inhibitors or angiotensin receptor blocking agents than diabetes patients without SMI. ${ }^{66}$ In a large VA study $(N=313,586)$ of people with diabetes, failure to meet diabetes performance measures was more common among people with mental illnesses, adjusting for various confounders, with AOR1.17 (1.15-1.20) for poor glycemic control, AOR1.20 (1.18-1.22) for poor lipid control, AOR1.23 (1.20-1.26) for no hemoglobin A1c testing, and AOR1.25 (1.23-1.28) for no LDL cholesterol testing. ${ }^{61}$

Several studies speculate whether access to care, care coordination, provider biases, or patient-specific factors contribute to the poor diabetes care for this population. ${ }^{67,68}$ Interestingly, although diabetes-specific knowledge among people with comorbid SMI and diabetes is lower among people with diabetes without SMI, ${ }^{69}$ people with SMI appear to be receptive to medication and disease self-management strategies when these are available. ${ }^{67,68,70} \mathrm{~A}$ large VA study $(N=22,014)$ found that adherence to oral hypoglycemic medications was actually better among diabetes patients with schizophrenia than patients without schizophrenia (57\% vs. $48 \%, p<0.001) .{ }^{71}$ Additionally, people with schizophrenia attend weight loss programs if these are provided, ${ }^{72-74}$ although whether their attendance rates are comparable to those without SMI has not been studied.

\section{Particularly Vulnerable Subpopulations with SMI}

Racial and Ethnic Minorities. No studies have been large enough to meaningfully examine differences in metabolic risk between racial/ethnic populations with SMI. This is a major oversight considering the differential rates of metabolic abnormalities among diverse samples in NHANES. ${ }^{19,75}$ In addition, significant disparities in quality of care for minority populations are well documented. ${ }^{76-79}$ Below, we review what is currently known about risk of diabetes and other cardiovascular diseases and treatment of these risks among minorities with SMI:

- Increased risk for diabetes and other cardiovascular disease risk factors: Small studies suggest that some minority groups with SMI are particularly susceptible to metabolic side effects resulting from antipsychotic medications, especially SGAs like olanzapine and clozapine, making screening of minority subpopulations particularly important. ${ }^{80-84}$ For example, in a casecontrol study examining California Medi-Cal beneficiaries between 1995 and 2000 exposed to both FGA and
SGA medications, African Americans with schizophrenia were at significantly higher risk than white, nonHispanics to develop diabetes [AOR $1.6(1.4-1.8)] .^{82} \mathrm{In}$ a 10-year naturalistic study of people treated with the clozapine, African Americans and Hispanics had elevated risk of developing diabetes compared to Whites $(\mathrm{AOR}=11.5 \quad(95 \%$ CI 3.59-36.88), $p=0.0001$; $\mathrm{AOR}=4.3(95 \% \mathrm{CI} 1.19-15.55), p=0.027$, respectively). ${ }^{85}$ In a large study of older veterans with schizophrenia taking FGA or SGA medications, African Americans had increased odds of elevated blood glucose levels suggestive of diabetes (OR 1.19, 95\%CI 1.05-1.36, $p<0.01) .{ }^{36}$ Another study of Medicare enrollees with schizophrenia $(N=14,182)$ found that African Americans with schizophrenia had significantly higher rates of diabetes than Caucasians $(15.5 \%$ vs. $11.7 \%$, $p<0.001$ ), even before the wide-spread use of SGA medications. ${ }^{27}$ Small studies found a higher prevalence of the metabolic syndrome among Hispanics with SMI taking antipsychotics, ranging from $35 \%$ to $74 \%{ }^{86,87}$ However, other studies have yielded conflicting resultswith no statistically significant differences between racial/ ethnic groups. ${ }^{88}$ These mixed findings demand examination in a large diverse prospective cohort study.

- Treatment of diabetes and other cardiovascular disease risk factors: An administrative database analysis of Medicaid recipients taking risperidone $(N=51,330)$ or olanzapine $(N=51,302)$ revealed that African American race was a significant predictor of diabetic ketoacidosis, indicating concerning under-detection and undertreatment of diabetes among this subpopulation. ${ }^{83}$ Hispanics with schizophrenia in CATIE had worse treatment rates for any metabolic abnormality (diabetes, hypertension, or dyslipidemia) when compared to nonHispanics $(21 \%$ vs. $39 \%) .{ }^{89}$

Youth. Children and adolescents appear to be particularly sensitive to metabolic side effects from SGAs. A retrospective cohort Medicaid study of 28,858 children or youth (6-24 years old) initiating antipsychotic medications $-87 \%$ taking SGAs, predominantly risperidone - was compared to 14,429 matched controls and found that users of antipsychotics had a threefold increased risk for type 2 diabetes $(\mathrm{HR}=3.03$ [95\% CI=1.73-5.32]), with a significantly increased risk with higher doses. ${ }^{90}$ When the cohort was restricted to children 6-17 years old, antipsychotic users had even higher risk of type 2 diabetes (HR 3.14 [95\%CI 1.50-6.56), with incidence increasing with higher doses. ${ }^{90}$ In another recent study of young adults (15-40 years old) with first-episode schizophrenia spectrum disorders, $15.4 \%$ (43/394) had hemoglobin Alc-defined prediabetes..$^{91}$

Women. In the Schizophrenia PORT field study $(N=719)$, Medicaid sample $(N=6066)$ and Medicare sample $(N=$ 
14,182), all found that women with schizophrenia had higher rates of diabetes than men (field study: $21.9 \%$ vs $10.8 \%$, $p<0.001$; Medicaid: $15 \%$ vs. $4.3 \%, p<0.001$; Medicare: $16.7 \%$ vs. $8.8 \%, p<0.001) .{ }^{27}$ In the CATIE trial, women with schizophrenia were found to have significantly higher rates of the metabolic syndrome than men [51.6 \% vs. $36.0 \%$, $p<0.0002] .{ }^{15}$ This finding is different than the general population, where the prevalence of diabetes is greater among men than women. ${ }^{92}$ To our knowledge, there are no clear explanations for this disparity in care. Nonwhite women in CATIE were especially vulnerable to undertreatment of dyslipidemia and diabetes compared to nonwhite men, ${ }^{89}$ which is consistent with the missed opportunity in treatment of diabetes for women in the general population. ${ }^{93}$

\section{Clinical and Policy Implications}

Given the premature mortality among people with SMI, strategies to reduce cardiovascular risk must be prioritized. Strategies can and should include:

1. Reducing antipsychotic medication dose or switching medications

2. Enhancing smoking cessation efforts

3. Sharing electronic health records between physical and mental health care systems

4. Promoting integration of care

Switching Antipsychotic Medications. There has been significant recent controversy between guidelines and systematic reviews on whether to change antipsychotics. Although ADA/APA guidelines recommended switching antipsychotic medications to those with lower metabolic risk, ${ }^{51}$ systematic reviews did not endorse switching medications to improve metabolic outcomes. ${ }^{67,94}$ In an updated literature review including two large RCTs, there is sufficient evidence supporting an elective switch from higher to lower metabolic risk antipsychotics (either FGA or SGA) to produce weight and lipid benefits without significant risk of clinical deterioration. ${ }^{42}$ When making an elective change of antipsychotic medications, we recommend careful risk/benefit assessment with the patient. ${ }^{42}$ Several strategies have been outlined to help clinicians switch to new antipsychotic medications. ${ }^{95}$ Each strategy has advantages and disadvantages, and the chosen strategy should be tailored to the individual patient. ${ }^{96,97}$ Studies also support a gradual discontinuation of the current antipsychotic medication - rather than abrupt discontinuation - in order to minimize decompensation early in the switching process. ${ }^{42}$ For primary care providers who are considering a switch of antipsychotic medications to achieve metabolic benefit, we recommend comparing metabolic side effect profiles (Table 1), considering either FGA or SGA medications, close consultation with a psychiatrist with experience in using a variety of antipsychotic medications, and closely monitoring mental health during cross titration. If switching is not preferred by the patient, appropriate ongoing discussion of the risks versus benefits of treatment is recommended. Finally, for patients receiving antipsychotics where evidence indicates a dose response associated with weight gain (e.g., olanzapine), clinicians could consider a slow taper to reduce metabolic complications while maintaining clinical stability. ${ }^{42}$

Take home point: It appears that most antipsychotics confer some risk, regardless of class, and our recommendation is to use medications with lower metabolic risk.

Enhancing Smoking Cessation Efforts. Although treatment of metabolic abnormalities is critical, nothing has a greater impact on reducing cardiovascular risk than smoking cessation. Given that over half of people with schizophrenia smoke, ${ }^{20-22}$ and smoking is a known risk factor for CVD,${ }^{24}$ it is vital that community mental health providers focus on smoking cessation. If pharmacological treatment is preferred, the strongest evidence for effective smoking cessation medications among people with schizophrenia lies with bupropion and smoking cessation counseling. ${ }^{67,98}$ In addition to pharmacological treatment, other behavioral interventions (e.g., motivational interviewing and cognitive behavioral therapy) appear promising for this vulnerable population. ${ }^{99-101}$

Take home point: Treat smokers with SMI with medications and/or groups.

Sharing Electronic Health Records. Most physical and mental health care systems operate in separate silos (digitally, financially,operationally), which makes managing healthcare among people with SMI challenging. ${ }^{3,4,102}$ Reliable capture of diagnostic information (mental and physical), actual laboratory values, accurate demographic information, and non-pharmacologic interventions (e.g., smoking cessation counseling) is often inconsistent across these separate databases. ${ }^{53,54,103,104}$ Unfortunately, multiple barriers - confidentiality, stigma, billing, and policy disincentives-impede integration of electronic health records between behavioral health and primary care providers. ${ }^{105}$ Unfortunately, the Behavioral Health Information Technology Act (S. 1517), which aimed to extend Medicaid and Medicare incentive funds to mental health providers and facilities that demonstrated meaningful use of electronic health records, could have reduce health care disparities for this vulnerable population, but was deemed too costly. ${ }^{105}$ It is imperative that providers caring for people with SMI advocate locally and nationally for shared electronic medical records, which could drastically improve the care for this vulnerable population.

Take home point: Advocate for sharing electronic health records between public mental and physical health systems.

Integration of Care. Although community mental health clinics (CMHCs) provide services to the vast majority of 
people with SMI - more than 3.5 million adults served each year - close to $50 \%$ of these clinics do not have a standard primary care referral process. ${ }^{4,106}$ In addition, because of poor funding in certain regions, Community Health Clinics (CHC) serve this population without support of mental health providers. One way to ensure improved cardiovascular disease risk screening and care is to invest in integration of behavioral and primary care programs. Thankfully, there has been a renewed emphasis on this reintegration in the context of health care reform. ${ }^{62,107}$ However, a recent Cochrane review has failed to identify a leading evidence-based model to improve the medical care for people with severe mental illness. ${ }^{108}$

It is worth considering whether CMHCs should be the primary care medical home for this patient population. ${ }^{107}$ Primary care providers could, and should, be co-located in community mental health clinics to serve patients who are too psychotic or disorganized to access care in traditional primary care clinics. The SAMHSA-funded Primary and Behavioral Health Care Integration (PBHCI) Grant Program was a step in the right direction in providing some evidence of effective programs to improve the medical care of this population. ${ }^{109}$ Mixed results, economic constraints, and the lack of sustainability resulting from PBHCI programs calls for larger NIHfunded studies to examine these models rigorously. ${ }^{10}$

Although most psychiatrists are aware of the metabolic risk of antipsychotic medications, many psychiatrists are loathe to treat metabolic abnormalities identified upon screening. ${ }^{4,104}$ Given the logistic, regulatory, and financial challenges for many CMHCs in having on-site primary care, administrators could consider having psychiatrists initiate treatment for diabetes, hypertension and/or dyslipidemia with primary care consultant support. This model would effectively be "reverse" collaborative care ${ }^{111}$ (collaborative care is supported by over 20 RCTs as a program to screening and treatment of depression in primary care). ${ }^{112}$ Medication algorithms have been developed for psychiatrists, ${ }^{113}$ but these could benefit from less complexity, considering the culture shift required for psychiatrists to expand their scope of practice.

With regard to CHCs, many primary care providers are unaware of the ADA/APA recommendations for annual screening for diabetes among people taking SGAs, regardless of age or other predisposing factors. ${ }^{51,103}$ System-wide efforts to educate primary care providers of these guidelines and options for switching antipsychotic medications should be implemented.

Take home point: Models to improve the medical care received at CMHCs need to be developed since these are the default medical home for this population

Taking these recommendations into account and returning to the case, Dr. Barton decided to work on smoking cessation as a first step to reduce Mr. Ortiz' cardiovascular risk, since switching antipsychotic medications is not currently an option. She starts Mr. Ortiz on bupropion and encourages him to join a smoking cessation group being offered in the clinic. Dr. Barton also talked to the clinic's medical director, who gave her approval to initiate metformin to treat his pre-diabetes. Dr. Barton identified food insecurity and talked to Mr. Ortiz about affordable food choices to reduce his risk of diabetes. Dr. Barton's experience with this patient inspired her to join the integration of care committee in her local public health system and advocate for better health care for her patients. Currently, this committee is discussing which variables should be included into the electronic health record as part of meaningful use, and how to enhance communication between primary care and mental health.

\section{SUMMARY}

Adults with SMI die, on average, 25 years earlier than the general population, most often from premature cardiovascular disease. Antipsychotic medications contribute to this problem since many of these medications increase the risk of diabetes, hypertension, dyslipidemia, and obesity. These effects are generally highest for second generation medications like clozapine and olanzapine, and low potency first-generation antipsychotics like chlorpromazine. Despite national diabetes screening guidelines for people taking these medications, people with SMI are unlikely to receive screening for diabetes or other cardiovascular disease risk factors. Even when diabetes or other cardiovascular disease risk factors are identified, people with SMI are often undertreated. These disparities are even more evident for specific subpopulations of people with SMI, including minorities, women and youth. Potential clinical and policy solutions that should be considered include switching antipsychotic medications, encouraging smoking cessation, integrating electronic medical records, and promoting integration of care efforts.

Acknowledgements: Dr. Mangurian was supported by the National Institutes of Mental Health (1K23MH093689), the UCSF Hellman Fellows Award for Early-Career Faculty, and the National Center for Research Resources, the National Center for Advancing Translational Sciences, and the Office of the Director, National Institutes of Health, through UCSF-CTSI Grant Number KL2 RRO24130. Dr. Newcomer has received grant support from the National Institutes of Health, Otsuka America Pharmaceutical Inc. and Foundation2Recovery, consulting fees from Reviva Pharmaceuticals, and he serves on a Data Safety Monitoring Board for Amgen, outside the submitted work. Dr. Schillinger was supported by NIH Center grants P3O DK092924-01. Dr. Schillinger was supported by the NIH Center Grant from the National Institute of Diabetes and Digestive and Kidney Diseases for The Health Delivery Systems-Center for Diabetes Translational Research (CDTR) (P3ODK092924) and the NIH/National Institute of Minority Health and Health Disparities (NIMHD) Comprehensive Center of Excellence for Health and Risk in Minority Youth and Young Adults (P60MD006902). Its contents are solely the responsibility of the authors and do not necessarily represent the official views of NIH.

Corresponding Author: Christina Mangurian, MD, MAS; Zuckerberg San Francisco General, San Francisco, CA 94110, USA (e-mail: christina.mangurian@ucsf.edu).

Compliance with Ethical Standards:

Conflict of Interest: The authors declare no conflicts of interest. 


\section{REFERENCES}

1. Kessler RC, Berglund PA, Bruce ML, et al. The prevalence and correlates of untreated serious mental illness. Health Serv Res. 2001;36(6 Pt 1):987-1007.

2. U.S. Census Bureau. 2010 Resident Population. 2010 http://www.census.gov/. Accessed April 7, 2016.

3. Druss BG, von Esenwein SA. Improving general medical care for persons with mental and addictive disorders: systematic review. Gen Hosp Psychiatry. 2006;28(2):145-153.

4. Druss BG, Marcus SC, Campbell J, et al. Medical services for clients in community mental health centers: results from a national survey. Psychiatr Serv. 2008;59(8):917-920.

5. Colton CW, Manderscheid RW. Congruencies in increased mortality rates, years of potential life lost, and causes of death among public mental health clients in eight states. Prevent Chronic Dis. 2006;3(2):A42.

6. Saha S, Chant D, McGrath J. A systematic review of mortality in schizophrenia: is the differential mortality gap worsening over time? Arch Gen Psychiatry. 2007;64(10):1123-1131.

7. Olfson M, Marcus SC, Wilk J, West JC. Awareness of illness and nonadherence to antipsychotic medications among persons with schizophrenia. Psychiatr Serv. 2006;57(2):205-211.

8. United States Department of Health and Human Services. Mental health: A Report of the Surgeon General. Rockville, MD: Department of Health and Human Services, Substance Abuse and Mental Health Services Administration, Center for Mental Health Services. 1999.

9. Institute of Medicine. Committee on Crossing the Quality Chasm: Improving the Quality of Health Care for Mental and Substance-Use Conditions. Washington DC: National Academies Press; 2006.

10. Regenold WT, Thapar RK, Marano C, Gavirneni S, Kondapavuluru PV. Increased prevalence of type 2 diabetes mellitus among psychiatric inpatients with bipolar I affective and schizoaffective disorders independent of psychotropic drug use. J Affect Disord. 2002;70(1):19-26.

11. Baptista T, De Mendoza S, Beaulieu S, Bermudez A, Martinez M. The metabolic syndrome during atypical antipsychotic drug treatment: mechanisms and management. Metab Syndr Relat Disord. 2004;2(4):290-307.

12. Kroeze WK, Hufeisen SJ, Popadak BA, et al. H1-histamine receptor affinity predicts short-term weight gain for typical and atypical antipsychotic drugs. Neuropsychopharmacology. 2003;28(3):519-526.

13. Domino ME, Frank RG, Rosenheck R. The diffusion of new antipsychotic medications and formulary policy. Schizophr Bull. 2003;29(1):95-104.

14. Gallini A, Donohue JM, Huskamp HA. Diffusion of antipsychotics in the US And French markets, 1998-2008. Psychiatr Serv. 2013;64(7):680-687.

15. McEvoy JP, Meyer JM, Goff DC, et al. Prevalence of the metabolic syndrome in patients with schizophrenia: baseline results from the Clinical Antipsychotic Trials of Intervention Effectiveness (CATIE) schizophrenia trial and comparison with national estimates from NHANES III Schizophr Res. 2005;80(1):19-32.

16. Newcomer Jw. Metabolic syndrome and mental illness. Am J Manag Care. 2007;13(7 Suppl):S170-177.

17. Goff DC, Sullivan LM, McEvoy JP, et al. A comparison of ten-year cardiac risk estimates in schizophrenia patients from the CATIE study and matched controls. Schizophr Res. 2005;80(1):45-53.

18. Xu J, Kochanek KD, Murphy SL, Tejada-Vera B. National Vital Statistics Report, Centers for Disease Control, US Department of Health \& Human Services, Final Data for 2007. 2010.

19. Ford ES, Giles WH, Dietz WH. Prevalence of the metabolic syndrome among US adults: findings from the third National Health and Nutrition Examination Survey. JAMA. 2002;287(3):356-359.

20. McClave AK, McKnight-Eily LR, Davis SP, Dube SR. Smoking characteristics of adults with selected lifetime mental illnesses: results from the 2007 National Health Interview Survey. Am J Public Health. 2010;100(12):2464-2472.

21. de Leon J, Diaz FJ. A meta-analysis of worldwide studies demonstrates an association between schizophrenia and tobacco smoking behaviors. Schizophr Res. 2005;76(2-3):135-157.

22. Executive Summary of The Third Report of The National Cholesterol Education Program (NCEP) Expert Panel on Detection, Evaluation, And Treatment of High Blood Cholesterol In Adults (Adult Treatment Panel III). JAMA. 2001;285(19):2486-2497.

23. Prochaska JJ, Hall SM, Bero LA. Tobacco use among individuals with schizophrenia: what role has the tobacco industry played? Schizophr Bull. 2008;34(3):555-567.
24. Alberg AJ, Shopland DR, Cummings KM. The 2014 Surgeon General's report: commemorating the 50th Anniversary of the 1964 Report of the Advisory Committee to the US Surgeon General and updating the evidence on the health consequences of cigarette smoking. Am J Epidemiol. 2014;179(4):403-412.

25. Mauer BJ, Druss BG. Mind and body reunited: improving care at the behavioral and primary healthcare interface. J Behav Health Serv Res. 2010;37(4):529-542.

26. Osborn DP, Wright CA, Levy G, King MB, Deo R, Nazareth I. Relative risk of diabetes, dyslipidaemia, hypertension and the metabolic syndrome in people with severe mental illnesses: systematic review and metaanalysis. BMC Psychiatry. 2008;8:84.

27. Dixon L, Weiden $\mathbf{P}$, Delahanty $\mathbf{J}$, et al. Prevalence and correlates of diabetes in national schizophrenia samples. Schizophr Bull. 2000;26(4):903-912.

28. CfDCa P. National Diabetes Statistics Report: Estimates of Diabetes and Its Burden in the United States, 2014. Atlanta, GA: U.S. Department of Health and Human Services; 2014.

29. De Hert M, Mauri M, Shaw $\mathbf{K}$, et al. The METEOR study of diabetes and other metabolic disorders in patients with schizophrenia treated with antipsychotic drugs. I. Methodology. Int $\mathrm{J}$ Methods Psychiatr Res. 2010;19(4):195-210. doi:10.1002/mpr. 1322.

30. Holt RI, Peveler RC. Association between antipsychotic drugs and diabetes. Diabetes Obes Metab. 2006;8(2):125-135.

31. Bushe C, Holt R. Prevalence of diabetes and impaired glucose tolerance in patients with schizophrenia. Br J Psychiatry Suppl. 2004;47:S67-71.

32. McIntyre RS, Konarski JZ, Misener VL, Kennedy SH. Bipolar disorder and diabetes mellitus: epidemiology, etiology, and treatment implications. Ann Clin Psychiatry. 2005;17(2):83-93.

33. van Winkel R, De Hert M, Van Eyck $D$, et al. Screening for diabetes and other metabolic abnormalities in patients with schizophrenia and schizoaffective disorder: evaluation of incidence and screening methods. J Clin Psychiatry. 2006;67(10):1493-1500.

34. Barnett AH, Mackin P, Chaudhry I, et al. Minimising metabolic and cardiovascular risk in schizophrenia: diabetes, obesity and dyslipidaemia. J Psychopharmacol. 2007;21(4):357-373.

35. van Winkel R, De Hert M, Van Eyck D, et al. Prevalence of diabetes and the metabolic syndrome in a sample of patients with bipolar disorder. Bipolar Disord. 2008;10(2):342-348.

36. Copeland LA, Parchman ML, Zeber JE, Lawrence VA, Downs JR, Miller AL. Prediabetes assessment and follow-up in older veterans with schizophrenia. Am J Geriatr Psychiatry. 2010;18(10):887-896.

37. Manu P, Correll CU, van Winkel R, Wampers M, De Hert M. Prediabetes in patients treated with antipsychotic drugs. J Clin Psychiatry. 2012;73(4):460-466

38. Lambert TJ, Velakoulis D, Pantelis C. Medical comorbidity in schizophrenia. Med J Aust. 2003;178(Suppl):S67-70.

39. Newcomer JW. Second-generation (atypical) antipsychotics and metabolic effects: a comprehensive literature review. CNS Drugs. 2005;19(Suppl 1):1-93.

40. Sederer LI. New York State Office of Mental Health: SHAPE MEDS. In: Mangurian C, ed2011

41. Yood MU, DeLorenze G, Quesenberry CP Jr, et al. The incidence of diabetes in atypical antipsychotic users differs according to agent-results from a multisite epidemiologic study. Pharmacoepidemiol Drug Saf. 2009; 18(9):791-799.

42. Newcomer JW, Weiden PJ, Buchanan RW. Switching antipsychotic medications to reduce adverse event burden in schizophrenia: establishing evidence-based practice. J Clin Psychiatry. 2013;74(11): 1108-1120.

43. Daumit GL, Goff DC, Meyer JM, et al. Antipsychotic effects on estimated 10-year coronary heart disease risk in the CATIE schizophrenia study. Schizophr Res. 2008;105(1-3): 175-187.

44. Cohen T, Sundaresh S, Levine F. Antipsychotics activate the TGFbeta pathway effector SMAD3. Mol Psychiatry. 2013;18(3):347-357.

45. Herrick-Davis $\mathbf{K}$, Grinde E, Teitler $\mathbf{M}$. Inverse agonist activity of atypical antipsychotic drugs at human 5-hydroxytryptamine2C receptors. J Pharmacol Exp Ther. 2000;295(1):226-232.

46. Wang Q, Huang XF. Effects of chronic treatment of olanzapine and haloperidol on peptide YY binding densities in the rat brain. Exp Neurol. 2008;209(1):261-267.

47. Comings DE, Blum K. Reward deficiency syndrome: genetic aspects of behavioral disorders. Prog Brain Res. 2000;126:325-341.

48. Sakata T, Ookuma K, Fukagawa K, et al. Blockade of the histamine $\mathrm{H1}$ receptor in the rat ventromedial hypothalamus and feeding elicitation. Brain Res. 1988;441(1-2):403-407. 
49. Fukagawa K, Sakata T, Shiraishi T, et al. Neuronal histamine modulates feeding behavior through H1-receptor in rat hypothalamus. Am J Physiol. 1989;256(3 Pt 2):R605-611.

50. Alexander GC, Gallagher SA, Mascola A, Moloney RM, Stafford RS. Increasing off-label use of antipsychotic medications in the United States, 1995-2008. Pharmacoepidemiol Drug Saf. 2011;20(2):177-184.

51. American Diabetes Association, American Psychiatric Association, American Association of Clinical Endocrinologists, North American Association for the Study of Obesity. Consensus development conference on antipsychotic drugs and obesity and diabetes. Diabetes Care. 2004;27:596-601.

52. Mittal D, Li C, Williams JS, Viverito $\mathbf{K}$, Landes $\mathbf{R D}$, Owen $\mathbf{R}$. Monitoring veterans for metabolic side effects when prescribing antipsychotics. Psychiatr Serv. 2013;64(1):28-35.

53. Morrato EH, Druss B, Hartung DM, et al. Metabolic testing rates in 3 state Medicaid programs after FDA warnings and ADA/APA recommendations for second-generation antipsychotic drugs. Arch Gen Psychiatry. 2010;67(1): 17-24.

54. Essock SM, Covell NH, Leckman-Westin E, et al. Identifying clinically questionable psychotropic prescribing practices for medicaid recipients in new york state. Psychiatr Serv. 2009;60(12):1595-1602.

55. Morrato EH, Newcomer JW, Kamat S, Baser O, Harnett J, Cuffel B. Metabolic screening after the American Diabetes Association's consensus statement on antipsychotic drugs and diabetes. Diabetes Care. 2009;32(6): 1037-1042.

56. Haupt DW, Rosenblatt LC, Kim E, Baker RA, Whitehead R, Newcomer JW. Prevalence and predictors of lipid and glucose monitoring in commercially insured patients treated with second-generation antipsychotic agents. Am J Psychiatry. 2009;166(3):345-353.

57. Mangurian C, Vittinghoff E, Creasman J, Knapp P, Fuentes-Afflick E, Schillinger D. Diabetes screening among underserved adults with severe mental illness who take antipsychotic medications. JAMA Internal Med. 2015; In press.

58. Dall TM, Yang W, Halder P, et al. The economic burden of elevated blood glucose levels in 2012: diagnosed and undiagnosed diabetes, gestational diabetes mellitus, and prediabetes. Diabetes Care. 2014;37(12):3172-3179.

59. Tait KF, Marshall T, Berman J, et al. Clustering of autoimmune disease in parents of siblings from the Type 1 diabetes Warren repository. Diabet Med. 2004;21(4):358-362.

60. Diabetes Prevention Program Research G, Knowler WC, Fowler SE, et al. 10-year follow-up of diabetes incidence and weight loss in the Diabetes Prevention Program Outcomes Study. Lancet. 2009;374(9702):16771686.

61. Frayne SM, Halanych JH, Miller DR, et al. Disparities in diabetes care: impact of mental illness. Arch Intern Med. 2005;165(22):26312638.

62. Fleischhacker WW, Cetkovich-Bakmas M, De Hert M, et al. Comorbid somatic illnesses in patients with severe mental disorders: clinical, policy, and research challenges. J Clin Psychiatry. 2008;69(4):514-519.

63. Newcomer JW, Nasrallah HA, McIntyre RS, Vogel-Scibilia S. Elevating the standard of care in the management of cardiometabolic risk factors in patients with mental illness. Conclusion: summary and recommendations. CNS Spectr. 2008;13(6 Suppl 10):13-14.

64. McGinty EE, Baller J, Azrin ST, Juliano-Bult D, Daumit GL. Quality of medical care for persons with serious mental illness: a comprehensive review. Schizophr Res. 2015;165(2-3):227-235.

65. Correll CU, Druss BG, Lombardo I, et al. Findings of a U.S. national cardiometabolic screening program among 10,084 psychiatric outpatients. Psychiatr Serv. 2010;61(9):892-898.

66. Kreyenbuhl J, Dickerson FB, Medoff DR, et al. Extent and management of cardiovascular risk factors in patients with type 2 diabetes and serious mental illness. J Nerv Ment Dis. 2006;194(6):404-410.

67. Kreyenbuhl J, Buchanan RW, Dickerson FB, Dixon LB. The Schizophrenia Patient Outcomes Research Team (PORT): updated treatment recommendations 2009. Schizophr Bull. 2010;36(1):94-103.

68. Piette JD, Heisler M, Ganoczy D, McCarthy JF, Valenstein M. Differential medication adherence among patients with schizophrenia and comorbid diabetes and hypertension. Psychiatr Serv. 2007;58(2):207-212.

69. Dickerson FB, Kreyenbuhl J, Goldberg RW, et al. A 5-year follow-up of diabetes knowledge in persons with serious mental illness and type 2 diabetes. J Clin Psychiatry. 2009;70(7):1057-1058.

70. Krein SL, Bingham CR, McCarthy JF, Mitchinson A, Payes J, Valenstein M. Diabetes treatment among VA patients with comorbid serious mental illness. Psychiatr Serv. 2006;57(7):1016-1021.
71. Kreyenbuhl J, Dixon LB, McCarthy JF, Soliman S, Ignacio RV, Valenstein M. Does adherence to medications for type 2 diabetes differ between individuals with vs without schizophrenia? Schizophr Bull. 2010;36(2):428-435

72. Daumit GL, Dalcin AT, Jerome GJ, et al. A behavioral weight-loss intervention for persons with serious mental illness in psychiatric rehabilitation centers. Int $J$ Obes (Lond). 2011;35(8):1114-1123.

73. Brar JS, Ganguli R, Pandina G, Turkoz I, Berry S, Mahmoud R. Effects of behavioral therapy on weight loss in overweight and obese patients with schizophrenia or schizoaffective disorder. J Clin Psychiatry. 2005;66(2):205-212.

74. Mangurian C, Chaudhry S, Capitelli L, et al. Implementation of a weight loss program for Latino outpatients with severe mental illness. Community Ment Health J. 2012.

75. Ervin RB. Prevalence of metabolic syndrome among adults 20 years of age and over, by sex, age, race and ethnicity, and body mass index: United States, 2003-2006. National Health Stat Rep. 2009;13:1-7.

76. Smedley BD, Stith AY, Nelson AR. Unequal Treatment: Confronting racial and ethnic disparities in health care. Washington, DC: National Academies Press; 2003.

77. United States Department of Health and Human Services. Mental Health: A Report of the Surgeon General. Rockville, MD: US Department of Human Services, Substance Abuse and Mental Health Services Administration, Center for Mental Health Services; 2001.

78. Sentell T, Shumway M, Snowden L. Access to mental health treatment by English language proficiency and race/ethnicity. J Gen Intern Med. 2007;22(Suppl 2):289-293.

79. Chew LD, Schillinger D, Maynard C, Lessler DS. Glycemic and lipid control among patients with diabetes at six U.S. public hospitals. J Health Care Poor Underserved. 2008;19(4):1060-1075.

80. Ananth J, Venkatesh R, Burgoyne K, Gunatilake S. Atypical antipsychotic drug use and diabetes. Psychother Psychosom. 2002;71(5):244-254.

81. Henderson DC, Cagliero E, Copeland PM, et al. Glucose metabolism in patients with schizophrenia treated with atypical antipsychotic agents: a frequently sampled intravenous glucose tolerance test and minimal model analysis. Arch Gen Psychiatry. 2005;62(1):19-28.

82. Lambert BL, Chou C-H, Chang K-Y, Tafesse E, Carson W. Antipsychotic exposure and type 2 diabetes among patients with schizophrenia: a matched case-control study of California Medicaid claims. Pharmacoepidemiol Drug Saf. 2005; 14(6):417-425.

83. Ramaswamy K, Kozma CM, Nasrallah H. Risk of diabetic ketoacidosis after exposure to risperidone or olanzapine. Drug Saf. 2007;30(7):589-599.

84. Schneiderhan ME, Batscha CL, Rosen C. Assessment of a point-of-care metabolic risk screening program in outpatients receiving antipsychotic agents. Pharmacotherapy. 2009;29(8):975-987.

85. Henderson DC, Nguyen DD, Copeland PM, et al. Clozapine, diabetes mellitus, hyperlipidemia, and cardiovascular risks and mortality: results of a 10-year naturalistic study. J Clin Psychiatry. 2005;66(9):1116-1121.

86. Kato MM, Currier MB, Gomez CM, Hall L, Gonzalez-Blanco $\mathbf{M}$. Prevalence of metabolic syndrome in Hispanic and Non-Hispanic Patients with schizophrenia. Prim Care Companion J Clin Psychiatry. 2004;6(2):74-77.

87. Mangurian C, Goss E, Newcomer J. Metabolic screening and treatment preferences of Hispanic inpatients. Psychiatr Serv. 2010;61(11):11621163. doi:10.1176/appi.ps.1161.1111.1162.

88. Keenan TE, Yu A, Cooper LA, et al. Racial patterns of cardiovascular disease risk factors in serious mental illness and the overall U.S. population. Schizophr Res. 2013;150(1):211-216.

89. Nasrallah HA, Meyer JM, Goff DC, et al. Low rates of treatment for hypertension, dyslipidemia and diabetes in schizophrenia: data from the CATIE schizophrenia trial sample at baseline. Schizophr Res. 2006;86(13): 15-22.

90. Bobo WV, Cooper Wo, Stein CM, et al. Antipsychotics and the risk of type 2 diabetes mellitus in children and youth. JAMA Psychiatry. 2013;70(10):1067-1075. doi:10.1001/jamapsychiatry.2013.2053.

91. Correll CU, Robinson DG, Schooler NR, et al. Cardiometabolic risk in patients with first-episode schizophrenia spectrum disorders: baseline results from the RAISE-ETP Study. JAMA Psychiatry. 2014

92. Prevention CfDCa. National Diabetes Fact Sheet: General Information and National Estimates on Diabetes in the United States, 2011. Atlanta, Georgia: U.S. Department of Health and Human Services, Centers for Disease Control and Prevention; 2011.

93. Gregg EW, Gu Q , Cheng YJ, Narayan KM, Cowie CC. Mortality trends in men and women with diabetes, 1971 to 2000. Ann Intern Med. 2007;147(3):149-155. 
94. Mukundan A, Faulkner G, Cohn T, Remington G. Antipsychotic switching for people with schizophrenia who have neuroleptic-induced weight or metabolic problems. Cochrane Database Syst Rev. 2010(12):Cd006629.

95. Masand PS. A review of pharmacologic strategies for switching to atypical antipsychotics. Prim Care Companion J Clin Psychiatry. 2005;7(3):121-129.

96. Ganguli R. Rationale and strategies for switching antipsychotics. Am J Health Syst Pharm. 2002;59(22 Suppl 8):S22-26.

97. Masand PS, Berry SL. Switching antipsychotic therapies. Ann Pharmacother. 2000;34(2):200-207.

98. Tsoi DT, Porwal M, Webster AC. Interventions for smoking cessation and reduction in individuals with schizophrenia. Cochrane Database Syst Rev. 2013;2, CD007253.

99. Prochaska JJ, Hall SE, Delucchi K, Hall SM. Efficacy of initiating tobacco dependence treatment in inpatient psychiatry: a randomized controlled trial. Am J Public Health. 2014; 104(8):1557-1565.

100. Baker A, Richmond R, Haile $\mathbf{M}$, et al. A randomized controlled trial of a smoking cessation intervention among people with a psychotic disorder. Am J Psychiatry. 2006; 163(11):1934-1942.

101. Baker AL, Richmond R, Kay-Lambkin FJ, et al. Randomized controlled trial of a healthy lifestyle intervention among smokers with psychotic disorders. Nicotine Tob Res. 2015;17(8):946-954.

102. Lambert TJ, Newcomer JW. Are the cardiometabolic complications of schizophrenia still neglected? Barriers Care Med J Aust. 2009;190(4 Suppl):S39-42.

103. Mangurian C, Giwa F, Shumway M, et al. Primary care providers' views on metabolic monitoring of outpatients taking antipsychotic medication. Psychiatr Serv. 2013;64(6):597-599.

104. Parameswaran SG, Chang C, Swenson AK, Shumway M, Olfson M, Mangurian CV. Roles in and barriers to metabolic screening for people taking antipsychotic medications: a survey of psychiatrists. Schizophr Res. 2013;143(2-3):395-396.
105. McGregor B, Mack D, Wrenn G, Shim RS, Holden K, Satcher D. Improving Service Coordination and Reducing Mental Health Disparities Through Adoption of Electronic Health Records. Psychiatr Serv. 2015:appips201400095.

106. Copeland LA, Zeber JE, Wang CP, et al. Patterns of primary care and mortality among patients with schizophrenia or diabetes: a cluster analysis approach to the retrospective study of healthcare utilization. BMC Health Serv Res. 2009;9:127.

107. Amiel JM, Pincus HA. The medical home model: new opportunities for psychiatric services in the United States. Curr Opin Psychiatry. 2011;24(6):562-568.

108. Reilly S, Planner C, Gask L, et al. Collaborative care approaches for people with severe mental illness. Cochrane Database Syst Rev. 2013.

109. Druss BG, von Esenwein SA, Compton MT, Rask KJ, Zhao L, Parker RM. A randomized trial of medical care management for community mental health settings: the Primary Care Access, Referral, and Evaluation (PCARE) study. Am J Psychiatry. 2010;167(2):151-159.

110. Scharf DM EN, Hackbarth NS, Horvitz-Lennon M, Beckman R, Han B, Lovejoy SL, Pincus HA, Burnam MA. Evaluation of the SAMHSA Primary and Behavioral Health Care Integration (PBHCI) Grant Program: Final Report. 2013.

111. Shackelford JR, Sirna M, Mangurian C, Dilley JW, Shumway M. Descriptive analysis of a novel health care approach: reverse colocationprimary care in a community mental health "home". Prim Care Compan CNS Disord. 2013;15(5).

112. Lin EH, Tang L, Katon W, Hegel MT, Sullivan MD, Unutzer J. Arthritis pain and disability: response to collaborative depression care. Gen Hosp Psychiatry. 2006;28(6):482-486.

113. Vanderlip ER, Fiedorowicz JG, Haynes WG. Screening, diagnosis, and treatment of dyslipidemia among persons with persistent mental illness: a literature review. Psychiatr Serv. 2012;63(7):693-701. 